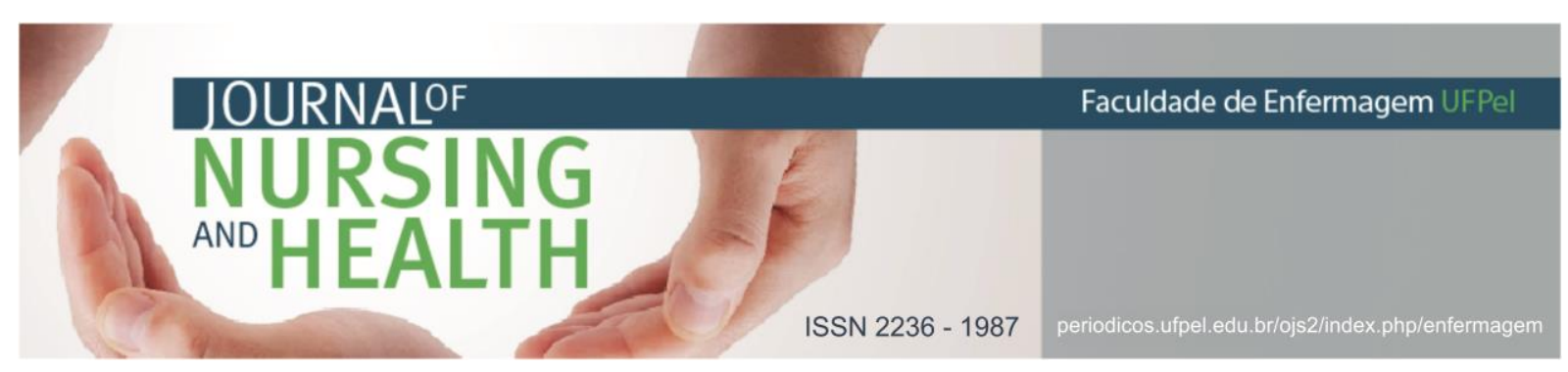

ARTIGO DE ATUALIZAÇÃO

\title{
O movimento internacional de ouvidores de vozes: as origens de uma tenaz prática de resistência
}

\author{
The international movement of voice hearing: the origins of a tenacious practice of \\ resistance
}
El movimiento internacional de oyentes de voces: los orígenes de una tenaz práctica de resistencia

Mario Cardano ${ }^{1}$

Como citar este artigo: Cardano M. O movimento internacional de ouvidores de vozes: as origens de uma tenaz prática de resistência. J. nurs. health. 2018;8(n.esp.):e188405.

\begin{abstract}
RESUMO
Objetivo: apresentar um resgate histórico e teórico do Movimento Internacional de Ouvidores de Vozes no contexto mundial. Métodos: foi realizada uma discussão teórica acerca do Movimento Internacional de Ouvidores de Vozes, buscando apresentar os marcos teóricos do movimento, assim como os principais autores que discutem sobre a temática. E ainda, refletir sobre a experiência de ouvir vozes. Resultados: o movimento nasce na Holanda, na segunda metade dos anos oitenta, para depois difundir-se, primeiramente na Europa e depois em todo o mundo, para chegar ao Brasil no ano passado, com o Congresso Nacional Ouvidores de Vozes em Saúde Mental, em 2017. Considerações finais: o movimento trata-se de um retorno que marca de forma evidente a transição do papel de paciente, com toda a carga de estigma associada a essa condição, ao de ouvidor que mostra saber transformar a própria experiência "insensata" em um saber capaz de curar: uma espécie de Nêmesis. Descritores: Saúde mental; Terapêutica; Sistemas de apoio psicossocial.
\end{abstract}

\begin{abstract}
Objective: to present a historical and theoretical rescue of the International Movement of Voice Hearing in the world context. Methods: a theoretical discussion about the International Movement of Voice Hearing was held, as well as the main authors who discuss the theme. Also, reflect on the experience of hearing voices. Results: the movement was born in the Netherlands in the second half of the 1980s and then spread to Europe, and later around the world, to arrive in Brazil last year, with the National Congress of Voice Hearing in Mental Health, in 2017. Final considerations: the movement is a return that clearly marks the transition from the role of the patient, with all the stigma associated with this condition, to the voice hearer who shows how to transform his own "insensate" experience into a knowledge capable of healing: a kind of Nemesis.

Descriptors: Mental Health; Therapeutics; Psychosocial support systems.
\end{abstract}

\footnotetext{
1 Professor Ordinario Dipartimento di Culture, Politica e Società- Università degli Studi di Torino. E-mail: mario.cardano@unito.it https://orcid.org/0000-0003-0268-3020
} 


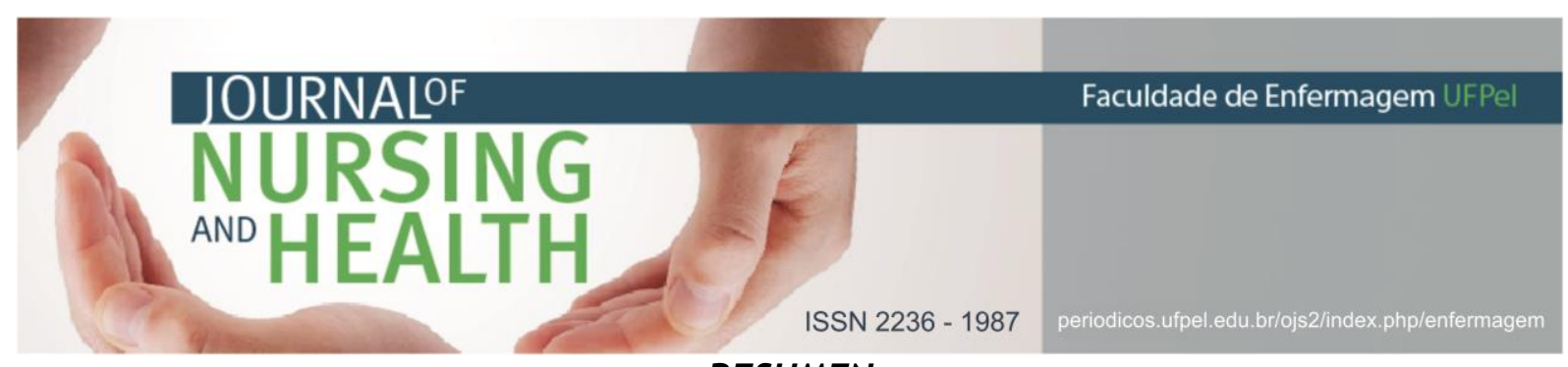

RESUMEN

Objetivo: presentar un rescate histórico y teórico del Movimiento Internacional de Oyentes de Voces en el contexto mundial. Métodos: se realizó una discusión teórica acerca del Movimiento Internacional de Oyentes de Voces, buscando presentar los marcos teóricos del movimiento, así como los principales autores que discuten sobre la temática. Y reflexionar sobre la experiencia de escuchar voces. Resultados: el movimiento nace en Holanda, en la segunda mitad de 1980, difundiéndose en Europa y después en todo el mundo, para llegar a Brasil el año pasado, con el Congreso Nacional Oidor de Voces en Salud Mental, en 2017. Consideraciones finales: el movimiento se trata de un retorno que marca de forma evidente la transición del papel de paciente, con toda la carga de estigma asociada a esa condición, al de oidor que muestra saber transformar la propia experiencia "insensata" en un saber capaz de curar: una especie de Némesis.

Descriptores: Salud mental; Terapéutica; Sistemas de apoyo psicosocial.

O movimento internacional dos Ouvidores de Vozes nasce na Holanda, na segunda metade dos anos oitenta, para depois difundir-se, primeiramente na Europa e depois em todo o mundo, para chegar ao Brasil no ano passado, com o Congresso Nacional Ouvidores de Vozes em Saúde Mental, em setembro de 2017.

Antes de continuar com a reconstrução da história deste que justamente - pode ser considerado como uma das mais tenazes práticas de resistência ao processo de medicalização das diversas formas de alteridade, uma concisa definição da experiência das vozes parece oportuna.

A experiência das vozes é, antes de tudo, uma experiência privada: faz parte do mundo próprio do ouvidor e não do mundo compartilhado pela mais vasta espécie humana. Enquanto que para as vozes comuns, com as quais é tecida a comunicação na vida cotidiana, é possível imaginar que um outro, no nosso lugar, possa ouvi-las e que, às vezes, ele possa reconhecer a pessoa da qual a voz provém; no caso das vozes de que nos ocupamos aqui, isso não acontece. A voz é ouvida apenas pelo ouvidor, que frequentemente não é nem capaz de identificar de forma clara a sua proveniência. Sob esse aspecto a experiência das vozes se assemelha à da dor física. A nossa dor é somente nossa, não podemos mostrá-la a outros, podemos - isso sim - falar dela, descrevê-la, mas ninguém nunca poderá senti-la como nós a sentimos. ${ }^{1}$

As vozes, além disso, são normalmente distinguidas, pelo ouvidor, das outras vozes e das mais comuns experiências de comunicação entre os homens. Maurice MerleauPonty descreve esse traço com uma imagem de particular eficácia. As alucinações, diz Merleau-Ponty, «desenvolvem-se sobre uma cena diferente do mundo percebido, estão como em sobreposição". Pouco mais adiante, o filósofo francês acrescenta: "A alucinação não é no mundo, mas “diante" dele» (ibidem). ${ }^{2}$ Tudo isso é confirmado na constatação documentada pela maior parte dos estudos dedicados ao tema das vozes de que os ouvidores, talvez não imediatamente, mas em um breve tempo aprendem a distinguir as vozes dos discursos proferidos por um falante 


\section{ISSN 2236 - 1987}

em carne e osso. É, portanto, impróprio pensar nas vozes como a uma percepção em todos os aspectos equiparável a todas as outras, exceto pelo fato de não se originarem a partir de um "objeto" que também os outros não podem reconhecer como tal. 0 conteúdo dessas vozes e o tom com o qual se dirigem ao ouvidor é extremamente variável, mas, como ensinam os ouvidores, profundamente ligados às histórias biográficas de quem ouve as vozes e ao contexto cultural dentro do qual essa experiência toma forma.

Aprendemos que as vozes se sobrepõem ao mundo do ouvidor de formas diversas: como uma espécie de voz fora de campo que comenta - ora bondosamente, ora não - os eventos; como um interlocutor que envolve o ouvidor em uma conversação; como uma voz disciplinante, que dá ordens, que comanda em tom categórico. Essa experiência "privada", mas não por isso irreal, é vivida, ao menos uma vez na vida, por cerca de 10-15\% da população ocidental. ${ }^{3}$ Entre todos esses, somente a metade requer a ajuda de um serviço de saúde mental. ${ }^{4}$ Se, então, dirigimos o olhar para além dos países industrializados, podemos observar como a experiência das vozes em muitas populações indígenas seja, não apenas difusa, mas também objeto de um especial reconhecimento social. É o caso dos xamãs das tribos siberianas ou dos índios americanos que, durante o luto pela morte de uma pessoa querida, ouvem a voz dela. Nesse aspecto comum se insere um conjunto diversificado de traços responsáveis pela heterogeneidade da experiência vivida das vozes. Viver com as vozes é diferente em razão do tempo transcorrido com elas e do sentido colocado nessa experiência (ver mais adiante).

Definida - sumariamente - a experiência das vozes, podemos voltar à Holanda, onde tudo começa, na relação entre uma paciente que ouvia «umas vozes na sua cabeça», Pasty Hage, e o seu psiquiatra, Marius Romme. Romme reconstrói essa passagem crucial da história no movimento dos ouvidores de vozes no volume Acpting voices, que escreveu com a esposa Sandra Escher. ${ }^{5}$ Romme conta como a própria paciente, a senhora Hage, atravessou um período particularmente crítico: assediada por vozes imperativas, que as doses maciças de neurolépticos que tomava não conseguiam extirpar. Prostrada pela ansiedade, a senhora Hage iniciou, cada vez mais, a expressar a vontade de tirar a sua vida, dirigindose para um precipício que somente um evento totalmente causal conseguiu contrastar. 0 evento em questão, um ponto de virada na «carreira moral» da senhora Hage, foi o encontro com o livro de um controverso psicólogo americano, Julian Jaynes, L'origine della coscienza e il crollo della mente bicamerale. ${ }^{6}$ A leitura dessa pesada monografia induziu a senhora Hage a olhar as vozes que a habitavam nela como nunca tinha feito antes, reconhecendo nessa sua diferença um modo de ser no mundo próprio dos heróis da Grécia antiga, celebrados por Homero, que tinham o privilégio de ouvir a voz dos deuses.

No livro que inspirou a senhora Hage a uma releitura da própria experiência, o autor, Julian Jaynes, sustenta claramente como, antes do 
ISSN 2236 - 1987

nascimento da psiquiatria, ouvir as vozes era considerado um fenômeno bastante comum e um fato bastante difundido: as antigas teocracias mesopotâmicas, egípcias e hebraicas se baseavam na autoridade da voz divina revelada e mediada pelos sacerdotes e pelos profetas; na Grécia antiga, o transe oracular era uma instituição difundida e objeto de veneração. Em época medieval, as vozes podiam ser atribuídas aos santos ou, em alguns casos, ao demônio, mas certamente não à loucura. A religião ocidental, católica em particular prossegue Jaynes - é permeada de vozes e deve a uma Voz, a de Deus, a revelação do código universal dos comportamentos humanos. 0 estudo de Julian Jaynes desenvolve a tese segundo a qual a experiência de ouvir vozes possa, de alguma forma, considerar-se vestígio de uma época em que a consciência humana, assim como hoje a conhecemos, não tinha ainda surgido. Ele afirma substancialmente que a consciência, que acreditamos conatural aos seres humanos, seja um produto bastante recente: "houve um tempo em que a natureza humana era dividida em duas partes: uma parte que dirige, chamada deus, e uma parte que se submete, chamada homem ${ }^{6}$, houve um tempo em que ouvir as vozes era a norma. Jaynes indica em um texto da classicidade grega, a llíada (um poema épico, atribuído a Homero), a representação plástica do funcionamento da mente bicameral. $\mathrm{Na}$ Ilíada - observa Jaynes - não está presente nem uma palavra que exprima o conceito de vontade. Os homens na llíada, portanto, não têm uma consciência, não tem uma vontade própria. Eles não têm momentos em que param para refletir sobre o que fazer. São os deuses a tomar o lugar da consciência: todas as suas ações não encontram o seu início em planos, razões e motivos conscientes, mas nas ações e nos discursos dos deuses. A mente dos heróis da llíada era - em extrema síntese - uma «mente bicameral», na qual um hemisfério cerebral hospedava as vozes dos deuses, que guiava as ações heroicas, ora de Aquiles, ora de Agamenon, ora de Menelau e de todos os heróis cantados por Homero. Em conclusão - escreve Jaynes - «o texto mais antigo da humanidade (...), se considerado de forma objetiva, revelanos uma forma mental muito diferente da nossa». Sobre a solidez filológica da interpretação de Jaynes do poema homérico, assim como sobre a consistência do modelo de mente proposto em Il crollo dellamente bicamerale, foram apresentadas numerosas e fundadas críticas. ${ }^{7}$ Isso, todavia, não tem importância aqui. 0 livro de Jaynes permanece relevante pela sua capacidade de inspirar um específico "contradiscurso" 8 sobre a experiência das vozes, um discurso capaz de desencadear o processo de desmedicalização ${ }^{9}$ de uma forma de alteridade profundamente «perturbante» como é a experiência das vozes.

Voltando à história de Pasty Hage, Romme recorda como, para a própria paciente, o fato de atribuir às próprias vozes uma origem, ao mesmo tempo remota e nobre, foi de grande conforto para ela. Partindo dessa constatação, Romme começou a se perguntar se esta sua paciente era capaz de comunicar a outros ouvidores 


\section{JOURNALOF \\ NURSING \\ AND HEALTH}

ISSN 2236 - 1987

pediu para contar a própria experiência em uma conferência, organizada em 31 de outubro de 1987, à qual participaram 360 ouvidores de vozes. Foi essa a primeira ocasião na qual a experiência das vozes foi contada e discutida em público em um contexto não medicalizante. Em seguida Romme e Escher participaram de uma conferência em Trieste (Itália), na qual encontraram Paul Baker, já ativo na defesa dos direitos dos chamados «sobreviventes da psiquiatria». Baker ficou impressionado com os resultados das pesquisas realizadas pelos estudiosos holandeses, e da sua interpretação da experiência das vozes. Em novembro do mesmo ano Baker foi convidado para a conferência de Mastricht (Holanda) intitulada "Pessoas que ouvem vozes", organizada pela Resonance Foundation (uma organização de autoajuda de ouvidores de vozes) e pelo Departamento de Psiquiatria Social da Universidade de Limburg. Baker ficou impressionado com a abordagem adotada e em particular com a ênfase colocada na aliança entre os Ouvidores de vozes e profissionais. O convite de Romme para essa conferência foi explícito: convido vocês para experimentar fazer a mesma coisa na Inglaterra. Em cada país devem ser constituídos grupos nos quais as pessoas possam falar conjuntamente sobre ouvir vozes, grupos de pessoas com a mesma experiência acabam por mudar comportamentos, na América e na Inglaterra, no momento, os psiquiatras se comportam como pais. 0 meu objetivo não é mudar a psiquiatria ou mudar os pais, mas oferecer aos 


\section{JOURNAIOF

ouvidores de vozes uma organização por meio da qual emancipar-se. ${ }^{5}$

Sucessivamente a esse encontro, Baker iniciará suas atividades na Inglaterra para difundir os estudos de Romme e Escher e para promover a rede dos ouvidores. Sucederam-se assim uma série de iniciativas públicas e foram iniciados os primeiros grupos de auto e mútua ajuda primeiramente na Holanda e na Inglaterra, mas com o passar do tempo também em outros países. Em novembro de 1990, ocorre em Manchester a primeira conferência do movimento, à qual se seguiram outras duas: em Londres, em março de 1991, novamente em Manchester, em setembro de 1991. Por último, em 1993 é oficialmente constituída a Rede Britânica dos Ouvidores de Vozes.

Foi fundado o The International Network for Training, Education and Research into Hearing voices (Intervoice), um network internacional para ouvidores de vozes que se propõe a conectar todas as iniciativas a favor dos ouvidores difundidas pelo mundo. Até o momento fazem parte da rede dos Ouvidores de Vozes, 21 países europeus, a Austrália, a Nova Zelândia, a Palestina, o Japão, o Canadá, os Estados Unidos, a Uganda e, desde 2017, também o Brasil. Na Europa estão ativos grupos de ouvidores de vozes na Áustria, Bélgica, Bósnia Herzegovina, Croácia, Dinamarca, Finlândia, França, Alemanha, Grécia, Irlanda, Itália, Malta, Noruega, Holanda, Portugal, Reino Unido, Sérvia, Eslovênia, Espanha, Suécia e Suíça. Concluo com algumas observações sobre os dois traços distintivos mais importantes do movimento dos ouvidores de vozes, as práticas de auto e mútua ajuda e os conteúdos do «contradiscurso» que as dão forma.

É possível reconhecer as raízes da prática de auto e mútua ajuda que caracteriza os grupos de Ouvidores presentes em todo o mundo na exortação de Marius Romme à própria paciente, Pasty Hage, para compartilhar com outros ouvidores a própria interpretação das vozes. Nos grupos dos ouvidores podemos compreender, expressos de forma particularmente nítida, os traços distintivos da auto e mútua ajuda. Antes de tudo, o compartilhamento da própria experiência - das vozes - entre pares, permite a cada um dos participantes amadurecer a convicção - tudo menos que óbvia - de não ser o único a viver uma experiência no mínimo singular. 0 confronto entre as diversas interpretações das vozes, qualquer que seja a sua plausibilidade, deixa amadurecer a convicção de que a explicação estigmatizante da psiquiatria de base biológica, que alude a alguma coisa que não funciona do cérebro do ouvidor, não seja a única possível. Além disso, a valorização de um saber experiente que não nasce da ciência, mas da experiência, torna possível apreender dos pares específicas estratégias de enfrentamento, antes, e aceitação, depois, das vozes. Por último, mas não menos importante, a experiência de poder ser útil a outros, com 0 compartilhamento do próprio saber e com a simples presença no grupo, permite 0 restabelecimento da autoestima. Cada um aprende que pode apoiar os próprios pares, que a própria experiência - frequentemente pontuada por sofrimentos profundos 


\section{IOURNAIOF \\ NURSING \\ AND HEALTH \\ ISSN $2236-1987$}

pode ajudar o outro a conviver com a própria diferença. Os grupos de Ouvidores se encontram com regularidade, normalmente em contextos informais, longe dos serviços psiquiátricos, e da sua condução (ou facilitação).

Ocupam-se principalmente de ouvidores que empregam 0 seu «saber por experiência» para promover a reconquista do controle sobre a vida de quem decide unir-se a eles.

0 contradiscurso que contradistingue o perfil cultural do movimento dos Ouvidores de Vozes compõe-se, essencialmente, de quatro movimentos dialéticos, os quais explico a seguir: i) a focalização; ii) a restituição das vozes à normalidade; iii) a atribuição de sentido; iv) a sua valorização. ${ }^{10} 0$ movimento dialético da focalização consiste na separação da experiência das vozes do mais vasto e heterogêneo conjunto de sintomas comumente atribuídos à patologia da qual as alucinações verbais constituem o traço distintivo, a esquizofrenia. Nos discursos dos ouvidores que tive oportunidade de analisar, assim como nestes - profissionais e acadêmicos que apoiam as razões deste movimento, a atenção recai quase exclusivamente sobre a experiência das vozes, examinadas ora nos seus conteúdos, ora na sua gênese, ora no seu impacto na vida cotidiana do ouvidor. Por outro lado, muito pouca atenção é dada à relação que as vozes mantêm com os outros distúrbios que, com as alucinações verbais, concorrem à composição do quadro sintomatológico da esquizofrenia, como as alterações do pensamento, da linguagem, do comportamento, da vontade, da atenção e da emotividade.
Escolhe-se, em uma frase, concentrar a atenção sobre um conjunto homogêneo de experiências, 0 das vozes, em vez de sobre um conjunto heterogêneo de sintomas, os atribuídos à esquizofrenia.

O segundo movimento dialético, implícito nas produções discursivas do Movimento dos Ouvidores de Vozes, conduz à restituição das vozes aos territórios da normalidade. Essa estratégia discursiva é reconhecível na quase totalidade dos discursos, por assim dizer, oficiais do Movimento dos Ouvidores, mas aparece também nas conversações comuns. Recordo que a primeira vez que encontrei Jacqui Dillon em Londres, ao apresentar-me as iniciativas da Rede que coordena, Jacqui definiu os ouvidores de vozes de forma simples e compacta: "differentminded people", uma expressão que, no contexto do nosso discurso, estava para "pessoas normais, mas com uma mente diversa". A mesma tese foi rebatida com uma singular eficácia comunicativa por Ron Coleman, na primeira Coordenação Nacional do Movimento dos Ouvidores de Vozes, ocorrido na cidade de Reggio Emilia (Itália), em 2008: «Ouvir vozes é uma experiência normal. É uma resposta normal a eventos anormais que podem acontecer na vida». Na mesma direção vão as conclusões de Lisa Blackman em um estudo sobre a rede britânica dos Ouvidores de Vozes, realizado nos anos noventa.

A Rede dos Ouvidores de Vozes move-se a partir da premissa pela qual ouvir as vozes é uma normal variante do comportamento, muito semelhante a ser canhoto e não o mero sinal de 


\section{IOURNALF

uma doença radicada em uma reação bioquímica do cérebro. ${ }^{11}$

A normalidade da experiência das vozes também é reivindicada remetendo-se à literatura etnológica ${ }^{12}$ que documenta como, em algumas culturas, a experiência de ouvir vozes seja, ao mesmo tempo, difusa e subsumida ao estigma. Da restituição das vozes à normalidade decorre - e não se trata de uma coisa qualquer - a autorização à sua escuta, a possibilidade de uma integração dentro da vida, da biografia do ouvidor. Tudo isso em aberta oposição com o discurso hegemônico dentro da psiquiatria, que se propõe a descontruir as vozes no plano ontológico e dissolver, com os medicamentos, aquele resíduo de "rumor" que permanece. Em uma frase, se a psiquiatria convencional se coloca contra as vozes, os Ouvidores de Vozes se propõem a viver com as vozes. ${ }^{11}$

Com o terceiro movimento dialético, a atribuição de sentido, as posições dos Ouvidores de Vozes assumem de modo mais completo a forma de "contradiscursos". 8 Em relação a isso é oportuno evidenciar o caráter plural dessas produções discursivas, e a sua pacífica convivência dentro do variegado universo cultural dos Ouvidores. Além da variabilidade que os contradistingue, estes contradiscursos se movem a partir de uma premissa comum: as vozes têm sentido, são muito mais do que um incômodo rumor de fundo, de uma casual composição de palavras. As vozes trazem um significado profundo, radicado na biografia do ouvidor; falam (e the falam) da sua vida, do seu modo de serno-mundo, das experiências que viveu. Esse significado, todavia, não se mostra de forma imediata, evidente. Parece, ao contrário, que as vozes se expressam de forma oblíqua, que revelam o seu significado recorrendo a uma linguagem metafórica ${ }^{12}$, que requer um árduo - e frequentemente doloroso - trabalho interpretativo para mostrar-se. 0 movimento dos Ouvidores sustenta fortemente a necessidade desse exercício interpretativo, em aberta oposição com a psiquiatria de base biológica, que exorta o paciente e as pessoas que tomam conta dele a ignorar as vozes. ${ }^{11}$ O saber empregado para dar forma a uma outra leitura das vozes é normalmente um saber ao qual a psiquiatria convencional reconhece pouca ou nenhuma legitimidade. É sem dúvida o caso da chave interpretativa das vozes que desencadeou o movimento dos Ouvidores, a extraída do livro de Julian Jaynes, Il crollo della mente bicamerale. Ainda mais distante do modelo da psiquiatria científica é o saber que inspirou de forma consistente as interpretações das vozes na primeira temporada do movimento dos Ouvidores, o que recorre ao mundo do paranormal e da espiritualidade em sentido amplo. Entram aqui as interpretações das vozes como expressão, ora de uma capacidade telepática, ora de uma sensibilidade mediúnica que se estende além dos limites da vida, mostrando-se como capacidade de escuta das vozes dos defuntos. ${ }^{11}$ Com o desenvolvimento e a difusão do movimento dos Ouvidores de vozes, as referências ao mundo do paranormal e da espiritualidade diminuíram, 


\section{JOURNALOF \\ NURSING \\ AND HEALTH}

ISSN 2236 - 1987

desde a mais tenra idade, iniciaram a habitá-la, para chegar a uma concepção não unitária de si, mas de todo ausente de toda conotação patológica. A esse respeito, Jacqui Dillon se exprime assim:

Comecei a me dar conta que era habitada por diversas pessoas. Essas "vozes" tinham diferentes nomes e identidade, diferentes $e$ distintas personalidades. Essa consciência gerou em mim um surpreendente conforto. A percepção da minha própria identidade mudou. Passei de ser "eu" a ser "nós". (...) Iniciei a compreender que as minhas vozes eram "si" dissociados que se constituíam como representações internalizadas do mundo no qual tinha crescido. Esses vários "si" tinham sido criados a partir da minha experiência. (...)Fiquei emocionada ao constatar o que a minha mente tinha conseguido inventar. Às vezes sentia que tinha criado uma obra de arte. ${ }^{12}$

O último movimento dialético na base do contradiscurso dos Ouvidores leva a uma explícita valorização da experiência das vozes. Os primeiros germes do processo de valorização das vozes mostram-se na elaboração de uma moldura interpretativa dessa experiência alternativa em relação àquela estigmatizante proposta pela psiquiatria tradicional. Tudo isso aparece de forma evidente nas origens do movimento dos ouvidores, com Pasty Hage que reivindica para si o privilégio dos heróis da antiga Grécia, o de poder ouvir a voz dos deuses. As vozes se configuram como um dom especial, como um carisma, em todas 
aquelas interpretações da sua gênese que fazem referência ao mundo do paranormal e, de forma geral, da mediunidade. É nessa chave que Cristina Contini leu as primeiras expressões da própria diferença, como a consequência de um «dom imenso» que tornou mais aguda a sua sensibilidade. ${ }^{14}$

Menos evidente, mas não por isso menos decisivo, é o processo de valorização da experiência das vozes que se move a partir da sua inscrição no registro mais laico, por assim dizer, da teoria do trauma. Do exame dos materiais que pude adquirir parece-me que posso reconhecer dois percursos paralelos. 0 primeiro percurso se entrevê nas palavras de Jacqui Dillon referidas mais acima. Dillon, em um agudo exercício de reflexividade, olha à própria vida e chega quase a regozijar-se com a capacidade que soube mostrar ao construir, em defesa da própria integridade, uma comunidade de "si", um «nós", contraposto ao «eu». Um exercício, acrescenta Jacqui Dillon, que assume os traços de uma verdadeira e própria «obra de arte». ${ }^{12}$

Essa confiança é reforçada no segundo percurso que configura uma forma particular de profissionalização da própria diferença, do carisma que a contradistingue. Esse percurso encontra uma eficaz ilustração nas histórias de uma outra ouvidora, Debra Lampshire, que dá o próprio testemunho no texto citado várias vezes, Living with voices. $\mathrm{Na}$ reconstrução do percurso que a conduz à recovery, à reconquista da sua vida, Debra reporta duas passagens-chave, que reproponho a seguir.
Foram anos mais tarde que decidi trabalhar no campo da saúde mental como consultora $e$ educadora. Aproximei-me de um clínico que pretendia iniciar grupos terapêuticos para ouvidores de vozes [...]. Encontrei o meu nicho. Tive a oportunidade de transformar $o$ que era um evento catastrófico em uma vocação que me permitiu aproveitar os aspectos positivos da vida. ${ }^{12}$

Debra Lamphsire utiliza com particular eficácia a imagem do nicho, que alude à individuação de um contexto - de certo modo protegido dentro do qual transformar a própria diferença em uma atividade profissional, dentro da qual tirar proveito do seu "saber por experiência" para guiar em direção ao processo de recuperação outras pessoas que, como ela, ouvem vozes. Trata-se, também, de um contexto no qual a sua nova identidade, a de facilitadora dos grupos de ajuda mútua, pode obter reconhecimento, pode encontrar no grupo de pessoas com as quais coopera - ouvidores e profissionais - legitimação. Esse peculiar processo, antes de tradução do estigma em carisma, e depois de profissionalização do carisma é reconhecivel nas biografias dos mais conhecidos líderes do movimento dos ouvidores, de Ron Coleman a Rufus May, de Jacqui Dillon a Cristina Contini e muitos outros ainda.

É difícil não evidenciar a peculiaridade desta última passagem do processo de valorização das vozes que leva os ouvidores que fazem essa experiência a habitar, embora com 


\section{ISSN 2236 - 1987}

papel e identidade especiais, o mundo da psiquiatria, dos serviços de saúde mental. Para alguns dos mais conhecidos facilitadores, principalmente, Ron Coleman, trata-se de um retorno aos lugares que os viram sujeitos de um poder psiquiátrico cego, incapaz de reconhecer o sentido da sua experiência. Trata-se de um retorno que marca de forma evidente a transição do papel de paciente, com toda a carga de estigma associada a essa condição, ao de ouvidor que mostra saber transformar a própria experiência "insensata" em um saber capaz de curar: uma espécie de nêmesis. 0 caráter paradoxal desse retorno atenua-se reconhecendo como, graças à presença de figuras profissionais caracterizadas por uma tão evidente alteridade, também o contexto dos serviços de saúde mental modifica os próprios contornos, aceitando - ao menos assim parece - o desafio ao paradigma diagnóstico, biomédico que provém do movimento dos Ouvidores de Vozes.

\section{REFERÊNCIAS}

1 Good BJ. Medicine, Rationality, and Experience: An anthropological perspective. Cambridge: Cambridge University Press; 1994.

2 Merleau-Ponty M. Fenomenologia da percepção. $1^{a}$ Edição. São Paulo: WMF Martins Fontes; 1945.

3 Jenner JA, Wiersma D. L'efficacia degli interventi psicosociali per le allucinazioni uditivo verbali. Riv sper freniatr med leg alien ment. 2006; CXXX(2): 111-139.
4 Romme M, Escher S. L'elaborazione di un diverso approccio sull'esperienza degli Uditori di voci. Riv sper freniatr med leg alien ment. 2006; CXXX(2): 141-165.

5 Romme M, Escher S. Accettare le voci. Le allucinazioni uditive: capirle e conviverci. Milano: Giuffrè Editore; 1997.

6 Jaynes J. Il crollo della mente bicamerale e l'origine della coscienza, Milano: Impramatur Editore; 2018.

7 Cavanna AE, Trimble $M$, Cinti $F$, Monaco F. The 'bicameralmind' 30 years on: a critical reappraisal of Julian Jaynes' hypothesis. Funct neurol. 2007; 22(1): 11-5.

8 Armostrong N, Murphy E. Conceptualizing resistance. Health: an interdisciplinary journal for the social study of health, illness and medicine. 2011; 16(3):314-26.

9 Conrad P. The medicalization of society: on the transformation of human conditions into treatable disorders. Baltimore: The Johns Hopkins University Press; 2007.

10 Cardano M, Lepori G. Udire la voce degli dei. Lesperienza del gruppo voci. Milano: Franco Angeli; 2012.

11 Blackman L. Hearing voices. Embodiment and experience. London/New York: Free Association Books; 2007.

12 Romme $M$, Escher S, Dillon J, Corstens D, Morris M. Living with voices. 50 stories of recovery. Herefordshire: PCCS Books Ltd; 2009.

13 Read J, van Os J, Morrison AP, Ross CA. Childhood trauma, psychosis and schizophrenia: a literature review with 


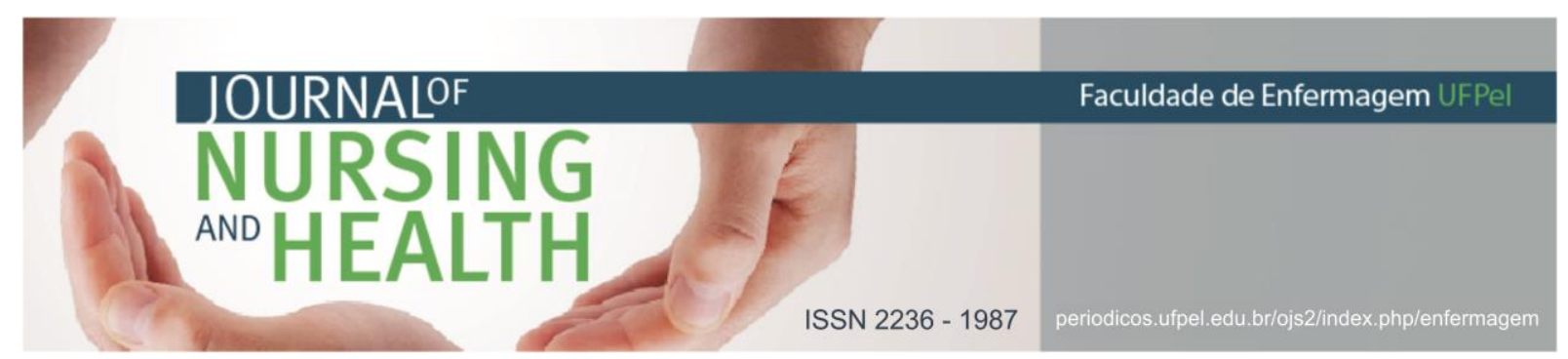

theoretical and clinical implications. Acta psychiatry scand. 2005; 112(1): 330-50.

14 Cardano M. Mental distress. Strategies of sense-making. Health: an interdisciplinary journal for the social study of health, illness and medicine. 2010; 14(3): 253-71.

Data de publicação: 19/09/2018 